\title{
Integration of High-Z Converter into Full-scale Production Target for Accelerator-based Production of ${ }^{99} \mathrm{Mo}$
}

Experimental Operations and Facilities Division 


\begin{abstract}
About Argonne National Laboratory
Argonne is a U.S. Department of Energy laboratory managed by UChicago Argonne, LLC under contract DE-AC02-06CH11357. The Laboratory's main facility is outside Chicago, at 9700 South Cass Avenue, Argonne, Illinois 60439. For information about Argonne and its pioneering science and technology programs, see www.anl.gov.
\end{abstract}

\title{
DOCUMENT AVAILABILITY
}

Online Access: U.S. Department of Energy (DOE) reports produced after 1991 and a growing number of pre-1991 documents are available free at OSTI.GOV (http://www.osti.gov/), a service of the U.S. Dept. of Energy's Office of Scientific and Technical Information

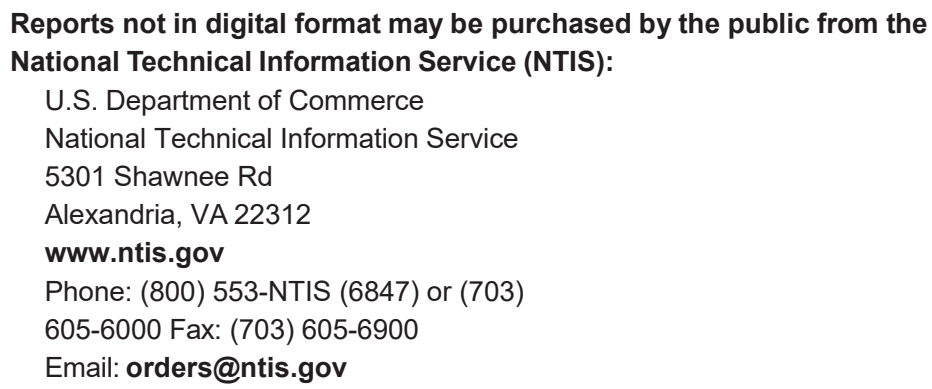

Reports not in digital format are available to DOE and DOE contractors from the Office of Scientific and Technical Information (OSTI):

U.S. Department of Energy

Office of Scientific and Technical Information

P.O. Box 62

Oak Ridge, TN 37831-0062

www.osti.gov

Phone: (865) 576-8401

Fax: (865) 576-5728

Email: reports@osti.gov

\section{Disclaimer}

This report was prepared as an account of work sponsored by an agency of the United States Government. Neither the United States Government nor any agency thereof, nor UChicago Argonne, LLC, nor any of their employees or officers, makes any warranty, express or implied, or assumes any legal liability or responsibility for the accuracy, completeness, or usefulness of any information, apparatus, product, or process disclosed, or represents that its use would not infringe privately owned rights. Reference herein to any specific commercial product, process, or service by trade name, trademark, manufacturer, or otherwise, does not necessarily constitute or imply its endorsement, recommendation, or favoring by the United States Government or any agency thereof. The views and opinions of document authors expressed herein do not necessarily state or reflect those of the United States Government or any agency thereof, Argonne National Laboratory, or UChicago Argonne, LLC. 
ANL-20/13

Integration of High-Z Converter into

Full-scale Production Target for

Accelerator-based Production of ${ }^{99} \mathrm{Mo}$

by

P. Strons, J. Bailey, A. Patapenka, S. Poremba, and S. Chemerisov

Experimental Operations and Facilities Division, Argonne National Laboratory

February 2020 



\section{CONTENTS}

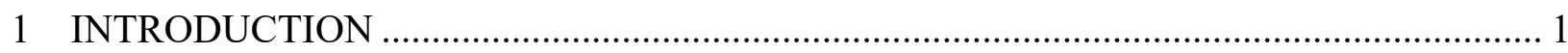

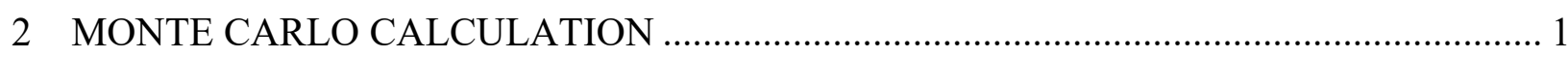

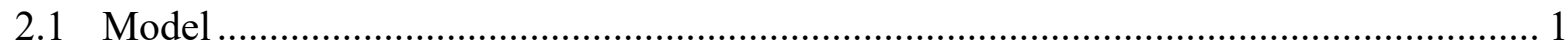

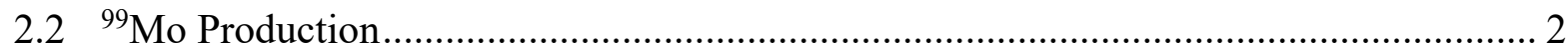

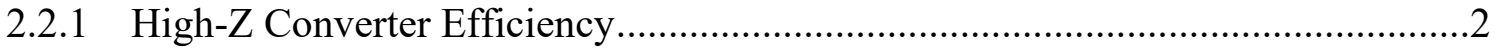

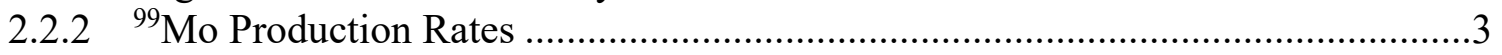

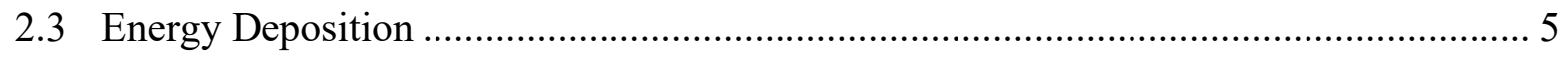

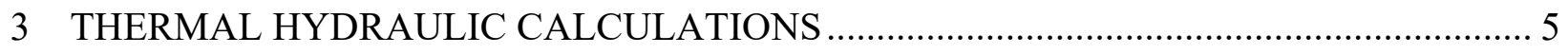

3.1 Computational Fluid Dynamics and Finite Element Analysis Models............................ 5

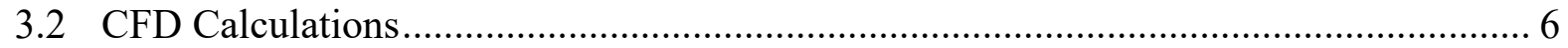

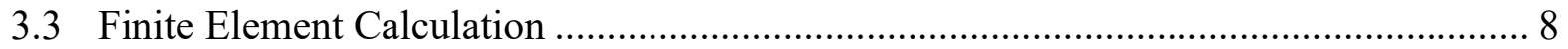

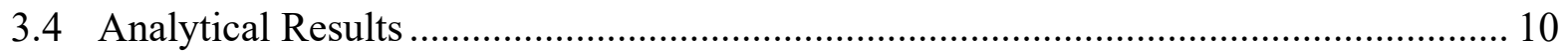

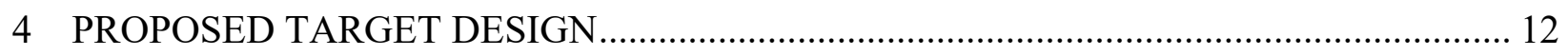

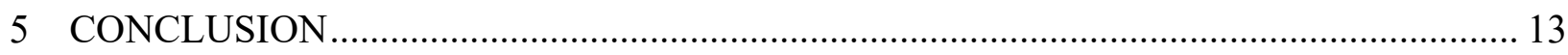

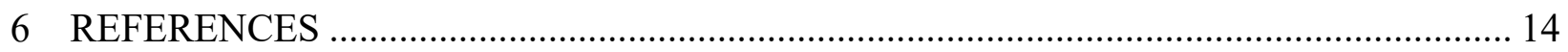

APPENDIX: ANALYTICAL CALCULATIONS FOR THE SECOND CONVERTER

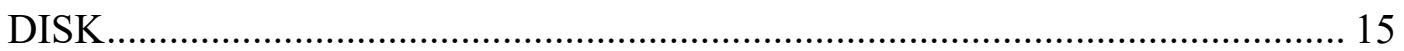

\section{FIGURES}

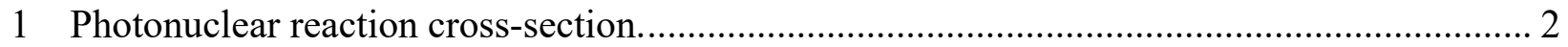

2 Relative efficiency of high-Z converters. The curve "thicknesses" show the statistical

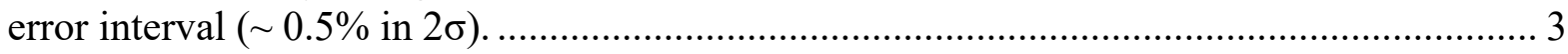

$3{ }^{99}$ Mo relative production rate in the target stack. Top left - configuration 1, top right configuration 2, bottom left - configuration 3, bottom right - configuration 4. ...................... 4

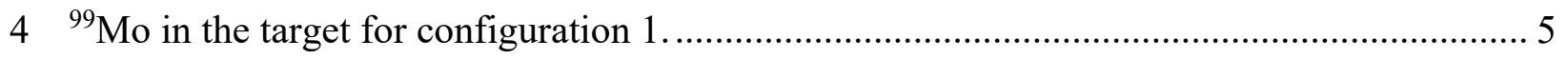

5 The geometry used in the CFD model to determine helium flow patterns and velocities.

6 Velocity contour through a horizontal section of the helium CFD model. Maximum velocity occurred at the central region between the window and the first disk., and helium velocity through the channels between disks was $112 \mathrm{~m} / \mathrm{s}$.

7 Velocity vector plot through a vertical section in the channel between the window and the first disk. The varying width of this channel caused an increase in helium velocity across the center of the window. 


\section{FIGURES (CONT.)}

8 The geometry used in the FE thermal model included the Inconel window and four disks. The first three disks were modeled as platinum converters, with the fourth disk modeled as a Mo target.

9 Temperature contour through the center of the first four disks of the assembly (three converters and then one target disk). The maximum temperatures in the disks were $952^{\circ} \mathrm{C}, 1499^{\circ} \mathrm{C}, 1643^{\circ} \mathrm{C}$, and $699^{\circ} \mathrm{C}$, respectively.

10 Temperature contour through the center of the Inconel window. Maximum temperature was $349^{\circ} \mathrm{C}$.

11 Temperature contours for disks 1 and 2. Both disks shown here are platinum converters.

12 Temperature contours for disks 3 and 4 . Disk 3 is a platinum converter and disk 4 is a

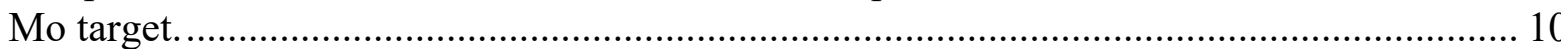

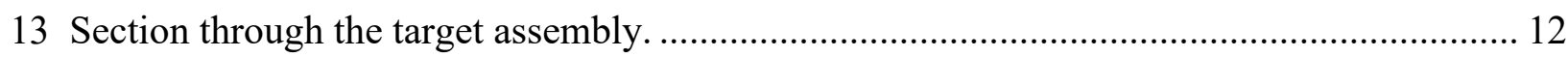

14 Details of the window and converter mounting............................................................... 13

\section{TABLES}

1 Simulated geometries and corresponding ${ }^{99}$ Mo production rates ...................................... 4

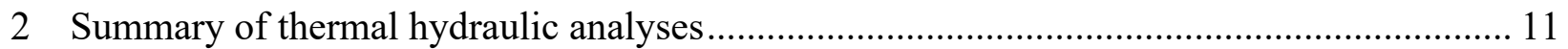




\section{INTRODUCTION}

NorthStar Medical Technologies is planning to produce the ${ }^{99}$ Mo isotope via the photonuclear route. The Rhodotron [1] accelerator designed by IBA will be used as an electronbeam source. The Rhodotron is an efficient recirculating accelerator, providing low energy dispersion and a low-emittance electron beam. The nominal beam power is assumed to be $120 \mathrm{~kW}$ at $40 \mathrm{MeV}$.

In photonuclear production of ${ }^{99} \mathrm{Mo}$, a high-power electron beam impinges on a heliumcooled Mo disk target. Electrons are converted into photons through the Bremsstrahlung process. Consequently, high-energy photons interact with the target nuclei, producing ${ }^{99}$ Mo through the

${ }^{100} \operatorname{Mo}(\gamma, n){ }^{99}$ Mo reaction. Traditionally, photonuclear production is realized using high-Z material as the electron-to-photon converter. NorthStar plans not to use a high-Z converter in the initial production target design, but it may be interested in the increased production capabilities a high- $Z$ converter can provide. The purpose of this report is to evaluate the advantages and disadvantages of incorporating a high- $Z$ converter into the target design.

\section{MONTE CARLO CALCULATION}

To calculate isotope production rates in the NorthStar Mo target, we used the FLUKA Monte Carlo code [2]. A set of simulations was performed to calculate the ${ }^{99}$ Mo production rate and energy deposition in the Mo target. The efficiency of heavy metallic converters and their impact on the production rates and energy deposition were also estimated.

\subsection{MODEL}

Nuclear interactions in FLUKA are simulated by the PEANUT $[3,4]$ model. The model includes not only hadron scattering off nuclei, but also the nuclear models for real and virtual photonuclear reactions.

The USRRNC routine from a set of "standard" FLUKA routines was used for calculations of residuals. The routine was precompiled with the FLUKA code and provided full information about the inelastic photonuclear reaction, i.e., the event location in the simulated geometry; residual mass, charge, energy and momenta; statistical weight of the reaction products and the projectile particle; reaction type; etc. The ${ }^{100} \operatorname{Mo}(\gamma, n)$ reaction cross-section calculated with FLUKA and the USRRNC routine is shown in Figure 1. The coincidence of the calculated results with EXFOR [5] data provides evidence of FLUKA's capabilities for isotope yield calculations. 


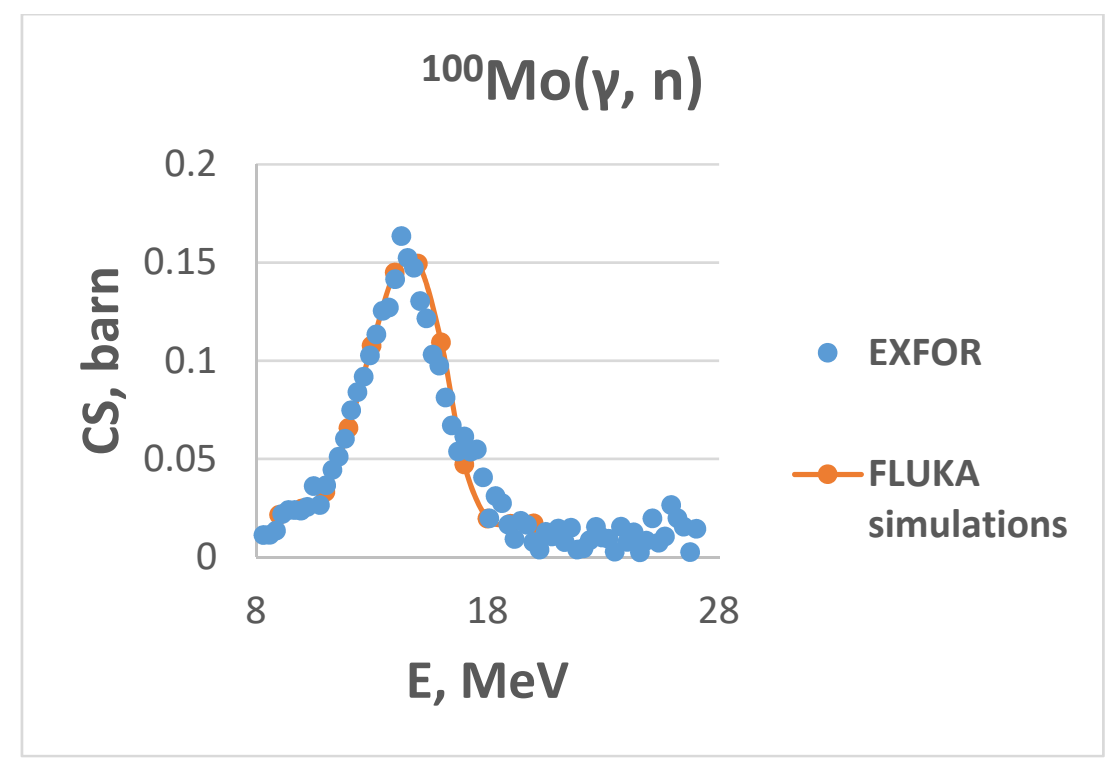

FIGURE 1 Photonuclear reaction cross-section.

For variance reduction, the inelastic nuclear interaction length of the photons was reduced by a factor of 100 inside the simulated materials (LAM-BIAS card in FLUKA).

As a particle source, we used two electron beams parallel to the $\mathrm{Z}$ local coordinate axis. We assumed that each beam has a Gaussian shape on both the $\mathrm{X}$ and $\mathrm{Y}$ axes, has a 12-mm FWHM, and provides $120 \mathrm{~kW}$ of power, or $1.872 \times 10^{16}$ electrons per second per beam.

As the material for the target, we used a composition consisting of $97 \%{ }^{100}$ Mo and $3 \%$ ${ }^{98}$ Mo isotopes. Currently, NorthStar is considering using sintered Mo disks as a target. For the material density, we used a value of $9.2 \mathrm{~g} / \mathrm{cc}$, considering that the porosity of the disk material is in the $8-10 \%$ range $[6]$.

Several configurations of the target were considered. The basic target geometry consisted of 82 Mo disks lined up perpendicular to two incident electron beams, one entering through the beam window on each side of the target stack. Each disk had a 29-mm diameter and $0.5-\mathrm{mm}$ thickness, and $0.25-\mathrm{mm}$ gaps separated the disks in the stack from each other for cooling. Additional heavy-metal disks with the identical geometrical parameters were simulated in order to estimate the high- $Z$ converter efficiency.

\section{$2.2{ }^{99}$ MO PRODUCTION}

\subsubsection{High-Z Converter Efficiency}

In order to estimate the efficiency of heavy metallic materials as bremsstrahlung converters, we added several disks to the target stack. Relative ${ }^{99}$ Mo production rates are shown 
in Figure 2. Three converter material were considered: platinum, tungsten and tantalum. All the materials were simulated with densities under normal conditions and natural isotope compositions. Taking into account the statistical uncertainties, it can be concluded that for the given basic target geometry, the maximal converter efficiency does not exceed $5.5 \%$. All three materials "work" similarly in a converter thickness range of $\sim 1.5 \mathrm{~mm}$, although platinum has minor advantages because of its density. The optimal converter thickness is in the range of $1-1.5 \mathrm{~mm}$.

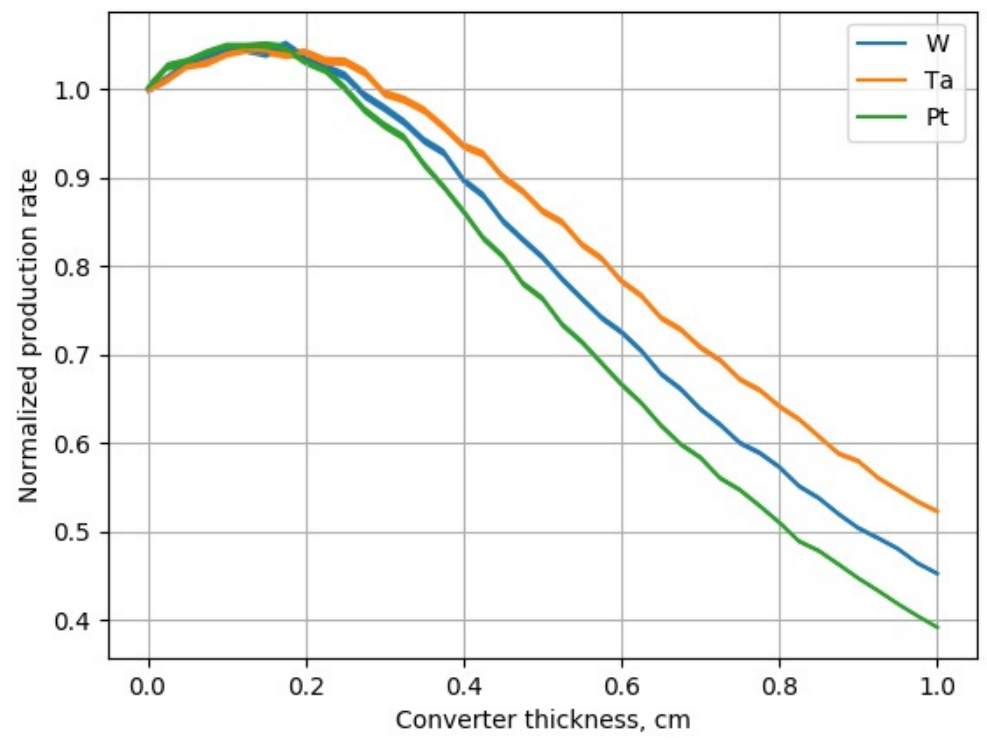

FIGURE 2 Relative efficiency of high-Z converters. The curve "thicknesses" show the statistical error interval $(\sim$ $0.5 \%$ in $2 \sigma)$.

\subsection{2 ${ }^{99}$ Mo Production Rates}

Simulation results are shown for ${ }^{99}$ Mo production rates (Table 1) and distribution of ${ }^{99}$ Mo nuclei in the target disks (Figure 3). The set of simulated geometries considered is listed in Table 1. 
TABLE 1 Simulated geometries and corresponding ${ }^{99}$ Mo production rates

Production Rate

Case

Configuration

[1/primary electron]

1 beam window 82 Mo disks | beam window

$2.22 \times 10^{-3}$

2* beam window $\mid 2$ Pt disks $\mid 82$ Mo disks $\mid 2$ Pt disks $\mid$ beam window

$2.33 \times 10^{-3}$

3* beam window $\mid 2$ Pt disks $\mid 78$ Mo disks $\mid 2$ Pt disks $\mid$ beam window

$2.28 \times 10^{-3}$

4* beam window $\mid 3$ Pt disks $\mid 76$ Mo disks $\mid 3$ Pt disks | beam window

$2.27 \times 10^{-3}$

* Converter disks have the same thickness as Mo disks. Total thicknesses of converter material are $1 \mathrm{~mm}, 1 \mathrm{~mm}$, and $1.5 \mathrm{~mm}$ from each side of the target for cases 2,3 and 4 , respectively.

As can be clearly seen in Figure 3, in addition to increasing the production rates, increasing the converter thickness makes the longitudinal distribution of ${ }^{99}$ Mo concentration more uniform.

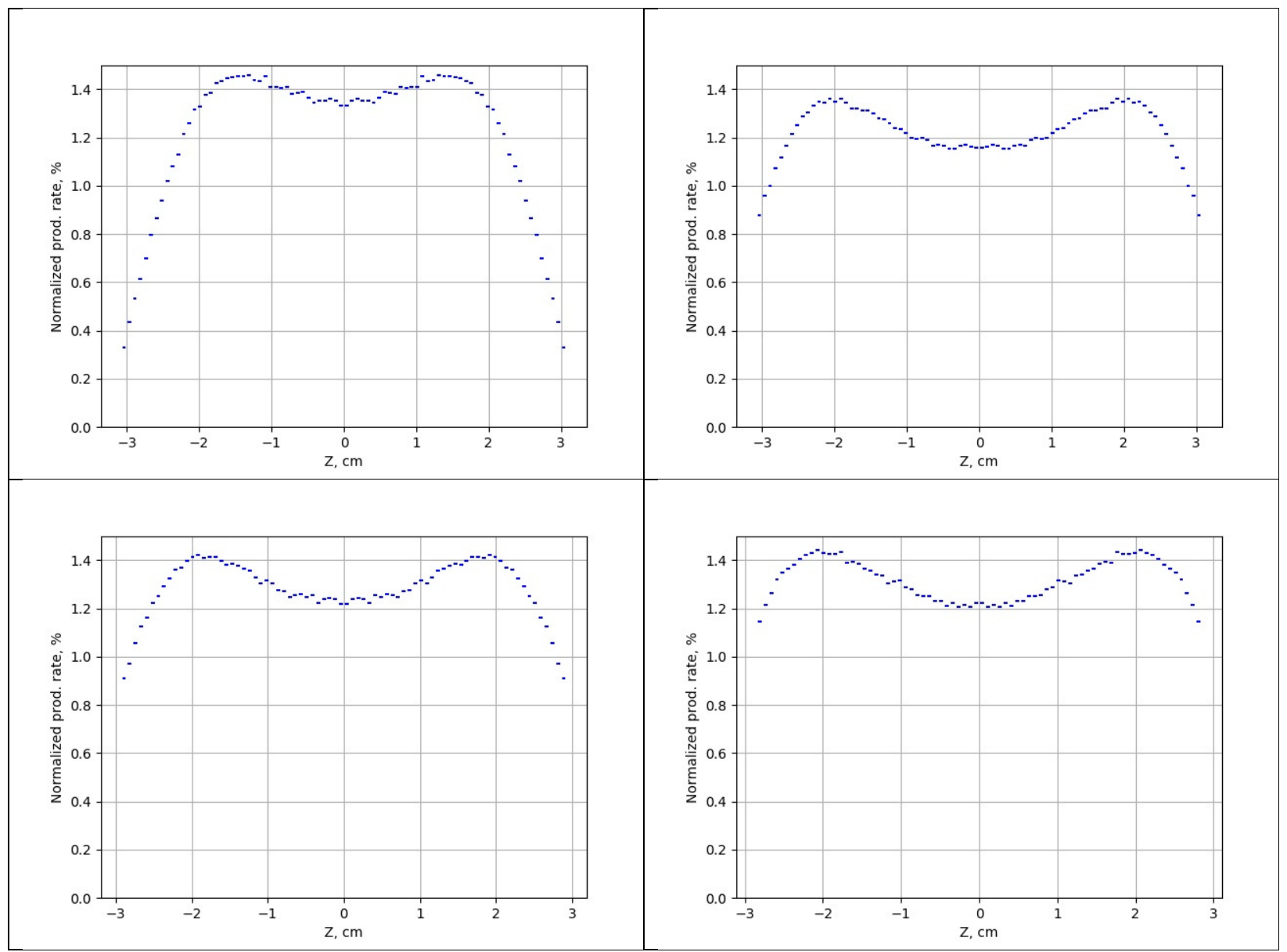

FIGURE $3{ }^{99}$ Mo relative production rate in the target stack. Top left - configuration 1, top right configuration 2, bottom left - configuration 3, bottom right - configuration 4 . 
Taking into account the beam parameters $-2 \times 120 \mathrm{~kW}, 40-\mathrm{MeV}$ electrons - it is easy to calculate ${ }^{99} \mathrm{Mo}$ accumulation in the full target assembly as a function of irradiation time (Figure 4).

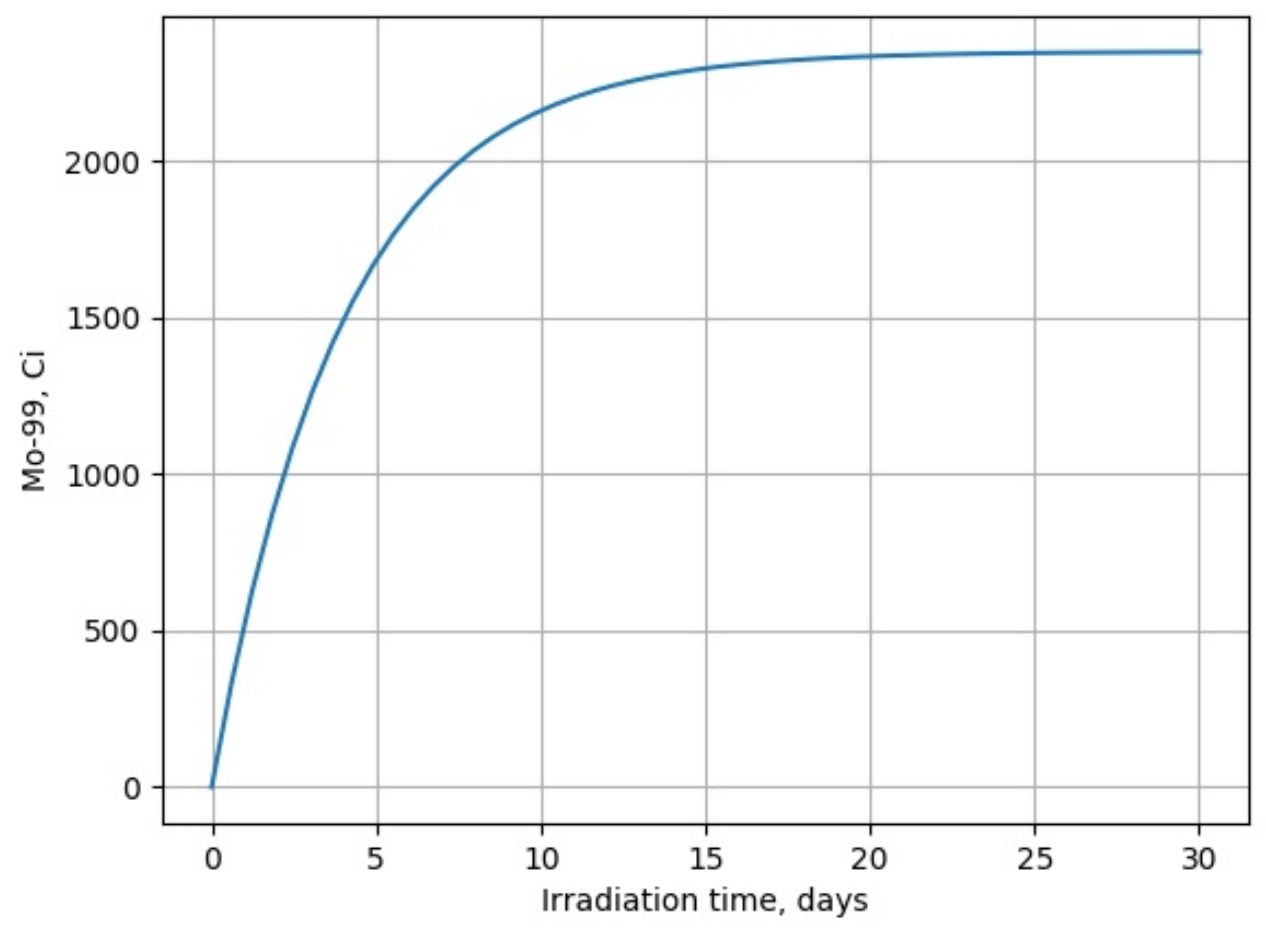

FIGURE $4{ }^{99}$ Mo in the target for configuration 1.

\subsection{ENERGY DEPOSITION}

For the study presented in this report, we use FLUKA for calculating the radiation energy deposition. As described above, we used two Gaussian-shaped 40-MeV electron beams as a source of primary particles. The energy deposition distribution was calculated in units of power and used in thermo-mechanical analysis and cooling-system studies.

\section{THERMAL HYDRAULIC CALCULATIONS}

\subsection{COMPUTATIONAL FLUID DYNAMICS AND FINITE ELEMENT ANALYSIS MODELS}

Modeling the heat transfer problem for the NorthStar target assembly was separated into two parts: a computational fluid dynamics (CFD) [7] model to obtain helium flow velocities and a thermal finite element (FE) analysis model to calculate temperature results. Although the CFD software can calculate heat transfer, the high element count needed to accurately model the 
helium flow made the solve times impractical for additional iterations examining multiple converter configurations. After the CFD solution of the helium flow was obtained, convective coefficients were calculated manually to use during multiple iterations in obtaining the final thermal solution for the converter disks evaluated in this report.

\subsection{CFD CALCULATIONS}

Geometries for both portions of the analysis were derived from files provided by NorthStar. For the helium fluid model, the target geometry provided by NorthStar included 0.25 $\mathrm{mm}$ flow channels between 0.50 -mm-thick target disks. A half-symmetrical model was used (Figure 5). The helium gas was modeled with an operating pressure of $2.068 \mathrm{MPa}(300 \mathrm{psi}$ ) and a mass flow rate of $150 \mathrm{~g} / \mathrm{sec}$ (half of $300 \mathrm{~g} / \mathrm{sec}$, due to symmetry).

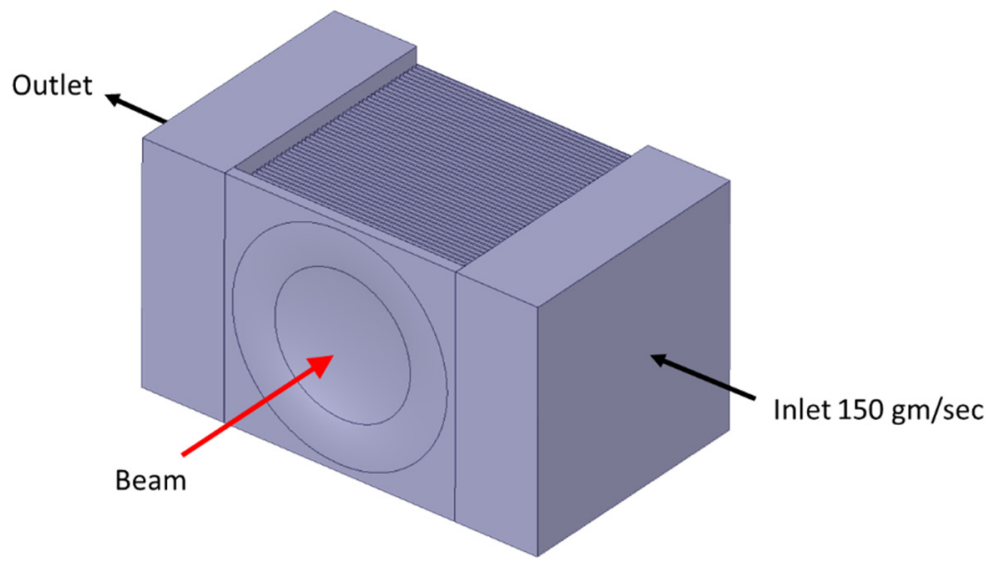

FIGURE 5 The geometry used in the CFD model to determine helium flow patterns and velocities.

The gap between the window and the first disk was modified from the original geometry. Initially, the spacing between the window and the first disk was $0.25 \mathrm{~mm}$ at its narrowest point, but it was modified to $0.15 \mathrm{~mm}$, providing an increase in helium velocity over the center of the window.

As shown in Figure 6, the velocity of the helium in the flow channels between target disks was evenly distributed, as expected, with a velocity of $112 \mathrm{~m} / \mathrm{s}$. Velocity across the window surface is shown in the vector plot of Figure 7. 

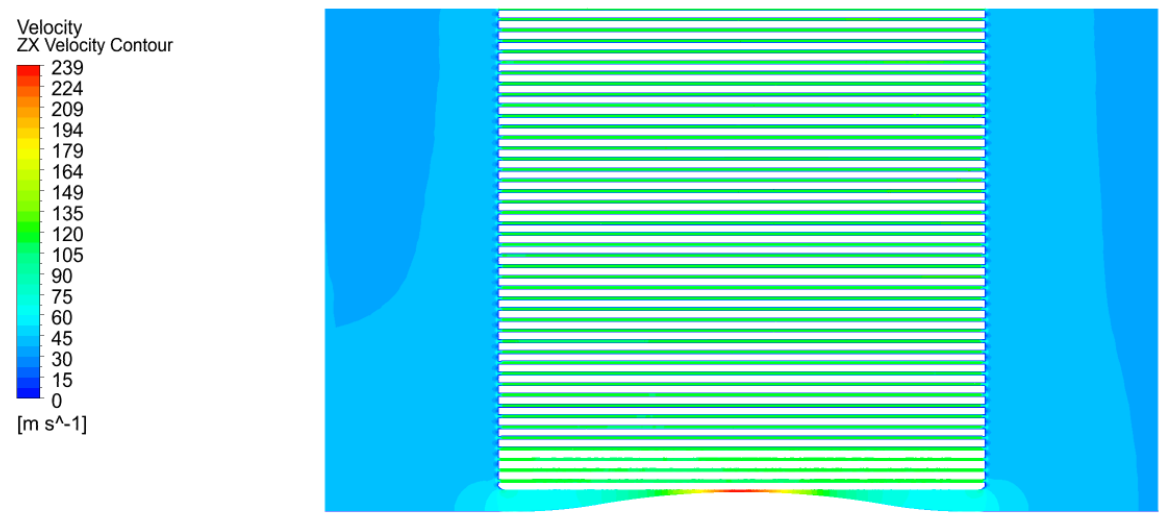

FIGURE 6 Velocity contour through a horizontal section of the helium CFD model. Maximum velocity occurred at the central region between the window and the first disk., and helium velocity through the channels between disks was $112 \mathrm{~m} / \mathrm{s}$.
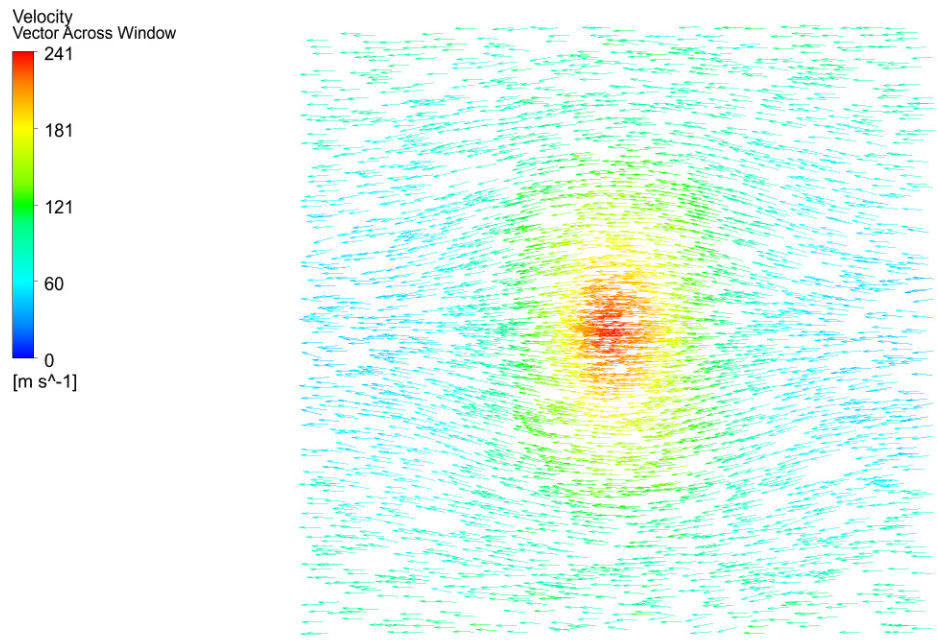

FIGURE 7 Velocity vector plot through a vertical section in the channel between the window and the first disk. The varying width of this channel caused an increase in helium velocity across the center of the window. 


\subsection{FINITE ELEMENT CALCULATION}

For the FE thermal model, only the solid bodies were meshed. The solid bodies in the model included the window and four disks (see Figure 8). Energy deposition from Monte Carlo simulations was applied as a tabular heat generation, and convective cooling boundaries were based upon manual calculations using velocities obtained from the previous CFD model. The window was assumed to be Inconel 718, converter disks were platinum, and the target disks were Mo. All materials were modeled with temperature-dependent thermal conductivity.

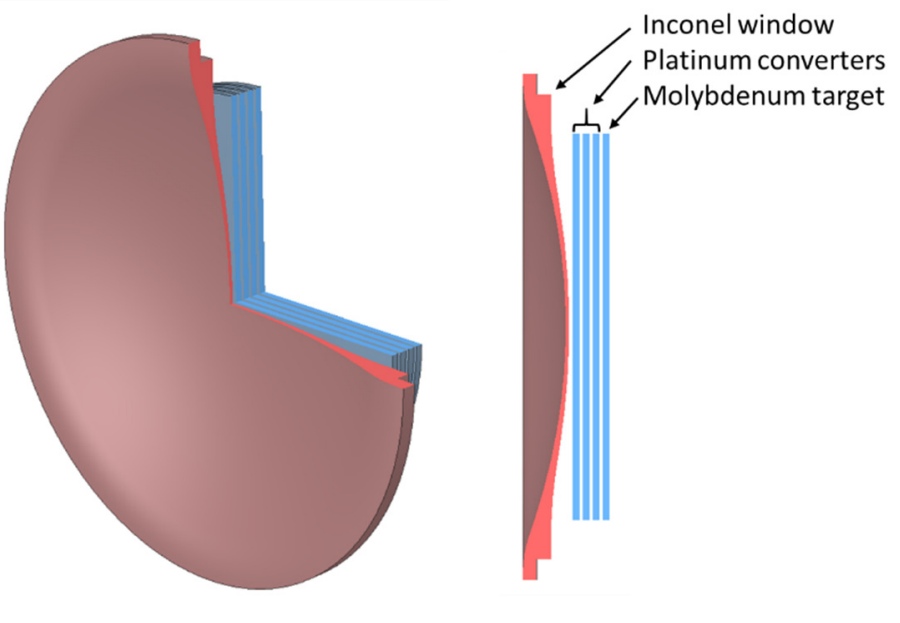

FIGURE 8 The geometry used in the FE thermal model included the Inconel window and four disks. The first three disks were modeled as platinum converters, with the fourth disk modeled as a Mo target.

The resulting temperatures for the window and disks are shown in Figures 9-12. The peak of the energy deposition occurs in the third converter disk, resulting in a maximum temperature of $1643^{\circ} \mathrm{C}$, which is $125^{\circ} \mathrm{C}$ below the melting point of platinum, $1768^{\circ} \mathrm{C}$. The maximum temperature in the window was $349^{\circ} \mathrm{C}$. 
O: Steady-State Thermal 3 Converter Discs

Temperature Pt Converter

Type: Temperature

Unit: ${ }^{\circ} \mathrm{C}$

Time: 1

1643.5 Max

1475

1125

950

775

600

250

56.76 Min

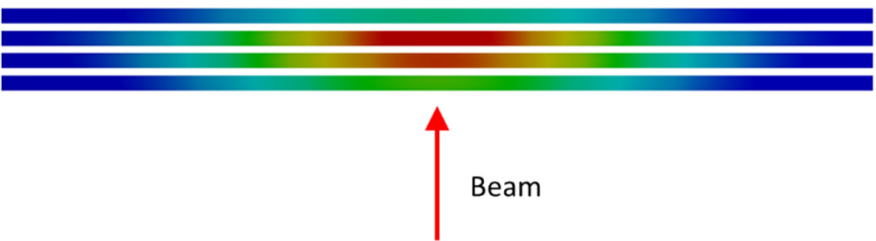

FIGURE 9 Temperature contour through the center of the first four disks of the assembly (three converters and then one target disk). The maximum temperatures in the disks were $952^{\circ} \mathrm{C}, 1499^{\circ} \mathrm{C}, 1643^{\circ} \mathrm{C}$, and $699^{\circ} \mathrm{C}$, respectively.

O: Steady-State Thermal 3 Converter Discs

Temperature Window 2

Type: Temperature

Unit: ${ }^{\circ} \mathrm{C}$

Time: 1

349 Max

315

280

245

210

140

105

69.4

34.4 Min

Beam

FIGURE 10 Temperature contour through the center of the Inconel window. Maximum temperature was $349^{\circ} \mathrm{C}$.

O: Steady-State Thermal 3 Converter Discs Temperature Pt Converter 1

Type: Temperature

Unit: ${ }^{\circ} \mathrm{C}$

Time: 1

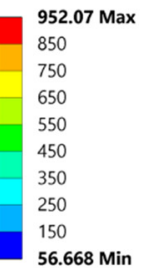

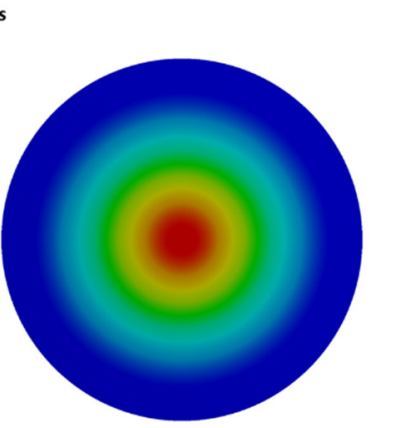

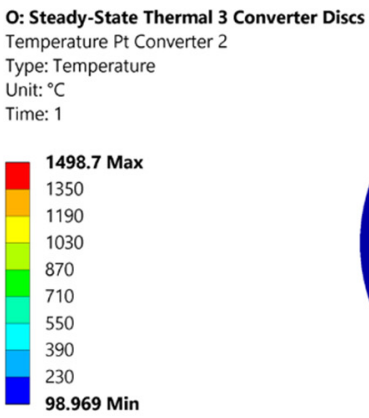

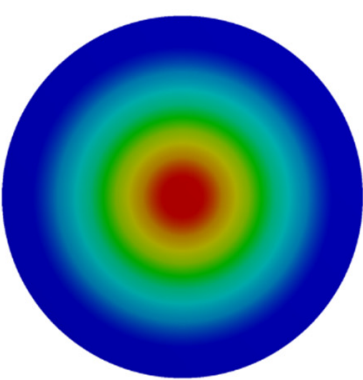

FIGURE 11 Temperature contours for disks 1 and 2. Both disks shown here are platinum converters. 

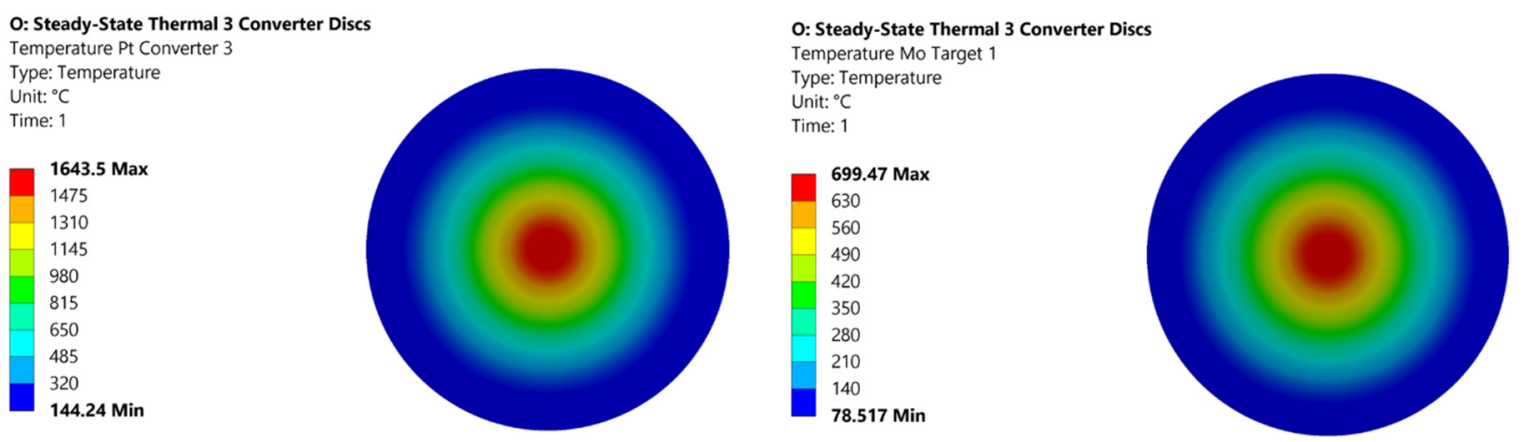

FIGURE 12 Temperature contours for disks 3 and 4. Disk 3 is a platinum converter and disk 4 is a Mo target.

\subsection{ANALYTICAL RESULTS}

The thermal convective coefficients at channel surfaces were determined using the average channel velocities obtain from the CFD hydraulic analysis and classical correlations for flow through a channel with parallel walls. The flow between the window and the first converter disk was determined to be $239 \mathrm{~m} / \mathrm{s}$, as obtained from the CFD calculations. The resulting convective coefficient at the center of the window was manually calculated to be 17.47 $\mathrm{kW} / \mathrm{m}^{2 \circ} \mathrm{C}$. As shown, the channel width varies across the diameter of the window, and as a result, the convective coefficient varies. However, it was found that this variation is small at the surface of interest, and hence, the coefficient was assumed constant, with the value as determined at the center. This convective coefficient value was used as a boundary condition (BC) for the FE heat transfer analysis of the window.

The flow between the disks was determined to be uniform, with an average velocity of $112 \mathrm{~m} / \mathrm{s}$. Considering this uniform flow and the equally spaced flow channels, the convective coefficient at the surface of all the disks was found to be $9.53 \mathrm{~kW} / \mathrm{m}^{2 \circ} \mathrm{C}$.

A sample manual calculation that describes the fluid properties, assumed correlations, and channel geometry of the second converter disk is shown in the Appendix.

A thermal analysis of the window and the first four disks was performed using a 1-D conduction heat transfer model. The purpose of this manual calculation was to provide an estimated check of the computer analysis results for FE heat transfer. The manually calculated thermal convective coefficients determined previously were used for the convective boundaries. An insulated boundary was assumed at the beam side of the window. The disks were modeled considering a half-symmetry insulated boundary opposite the convective boundary. The maximum heat generation densities at the center of the window and at the center of each disk were assigned the same values as those used in the FE heat transfer computer modeling.

A sample manual calculation that describes the thermal properties of the window and disks, the assumed heat transfer correlations, and modeling of the boundary conditions and internal heat generation is shown in the Appendix. 
Table 2 summarizes the input heat generation, convective boundary values, and resulting surface temperatures from the manual calculation as compared to the FE computer results.

TABLE 2 Summary of thermal hydraulic analyses

\begin{tabular}{llcrrr}
\hline \multicolumn{1}{c}{ Item } & Material & $\begin{array}{c}\text { Heat Gen. } \\
{\left[\mathrm{W} / \mathrm{m}^{3}\right]}\end{array}$ & $\begin{array}{c}\text { Conv. BC } \\
{\left[\mathrm{W} / \mathrm{m}^{2 \circ} \mathrm{C}\right]}\end{array}$ & $\begin{array}{c}\mathrm{T}_{\text {manual calc. }} \\
{\left[{ }^{\circ} \mathrm{C}\right]}\end{array}$ & $\begin{array}{c}\mathrm{T}_{\mathrm{FE} \text { analysis }} \\
{\left[{ }^{\circ} \mathrm{C}\right]}\end{array}$ \\
\hline Window & Inconel & $2.1662 \mathrm{E}+10$ & 17,470 & 331 & 349 \\
Disk 1 & $\mathrm{Pt}$ & $5.4570 \mathrm{E}+10$ & 13,500 & 1,032 & 952 \\
Disk 2 & $\mathrm{Pt}$ & $6.4710 \mathrm{E}+10$ & 9,530 & 1,719 & 1,499 \\
Disk 3 & $\mathrm{Pt}$ & $7.1382 \mathrm{E}+10$ & 9,530 & 1,894 & 1,644 \\
Disk 4 & Mo & $3.0723 \mathrm{E}+10$ & 9,530 & 827 & 700 \\
\hline
\end{tabular}

Note that the convective boundary at disk 1 has different values on either side of the disk. The average value was used for the 1-D heat transfer model.

As indicated in Table 2, the temperature differences between the manual calculations and the FE computer results for the four disks are within 15\%. The observation that the temperature results for the disks from the manual calculations are higher than the computer results is expected because the 1-D modeling does not account for the 2-D radial conduction away from the center. However, for the window, the manual calculation is about $5 \%$ lower than the computer results; this difference is caused by the assumption that the convective coefficient is uniform across the window. As discussed before, the channel width for the window channel varies across the diameter and therefore, the convective coefficient varies somewhat. The value of this coefficient was determined at the center of the window, where the convective coefficient is highest. Because this value is assumed across the entire window in the manual calculation, the overall temperature of the window is expected to be lower.

Solving for the helium flow was computationally challenging because of the geometry. Obtaining a reasonably accurate solution required a CFD mesh having tens of millions of elements. For the boundary conditions, a fixed mass flow boundary was set at both the inlet and outlet, as this approach was computationally expedient. Expedience was also the motivation for dividing the problem into separate CFD and FE analyses.

The calculated maximum temperature of the third converter disk was marginally higher than the melting point of the material $\left(1768^{\circ} \mathrm{C}\right)$. Further investigation that includes mesh refinement and improved boundary conditions would provide greater accuracy in calculated turbulent flow patterns and temperature results by reducing some of the conservatism used in the calculations presented in this report. Two-converter-disk configuration resulted in the same production yield for ${ }^{99} \mathrm{Mo}$, so only two-disc configuration is recommended for practical application. 


\section{PROPOSED TARGET DESIGN}

Figure 13 shows the overall arrangement of the target assembly. The assembly is located entirely within the beamline vacuum environment. The beams impinge on the targets from both sides, as shown. The thin beam windows provide the boundary between the vacuum and the pressurized helium. The converter plates are integral with the beam window mount and are separate from the target holder. This arrangement provides for removing the target plates without the converter plates. Pressurized helium is supplied and returned through tubes connected to the target housing. Channels between all plates allow for helium cooling on the plate surfaces.

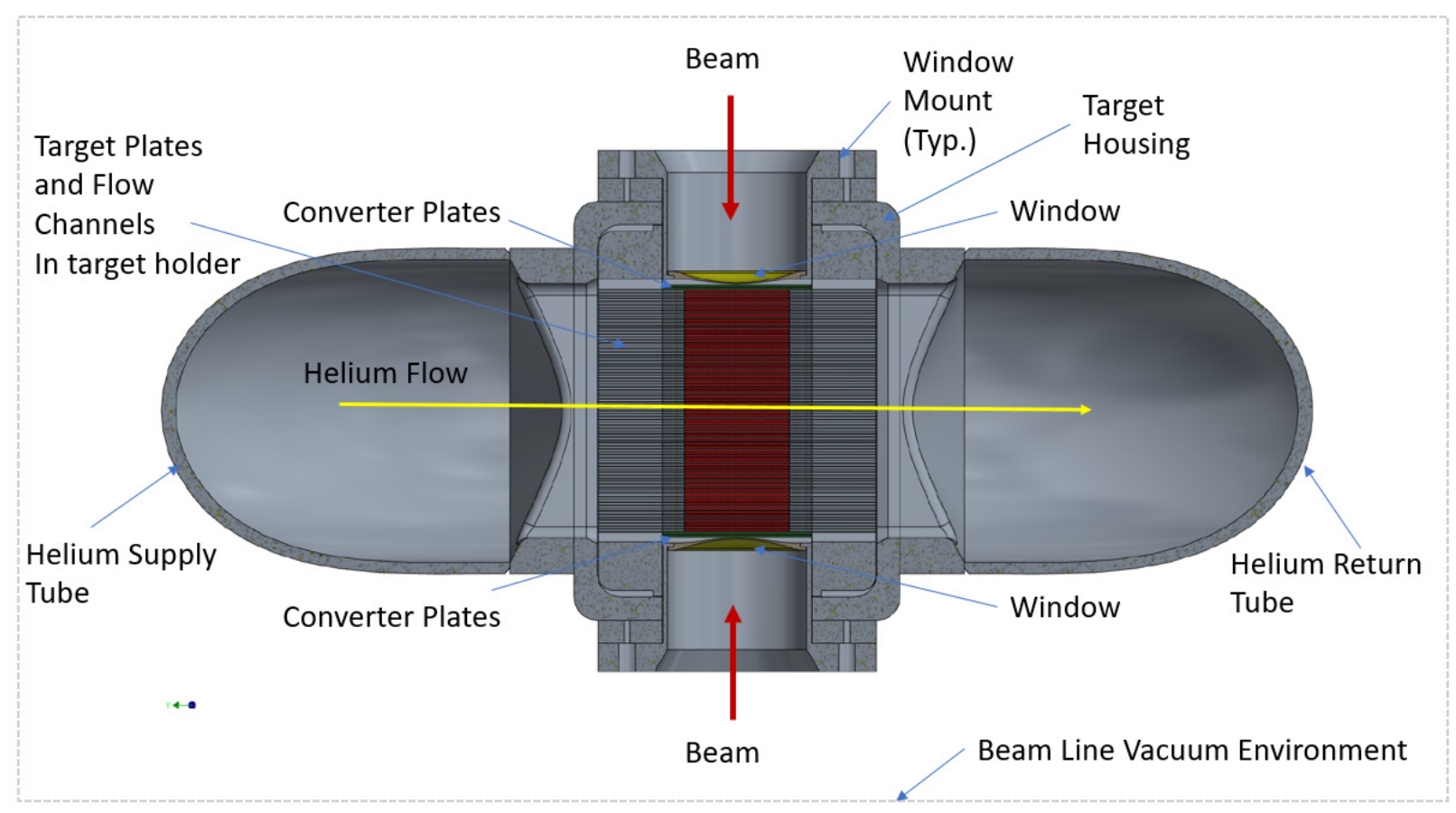

FIGURE 13 Section through the target assembly.

Figure 14 shows the details of the mounting of the beam window and converter plates. The window is spherical and is integral with the housing insert. The converter plates are fixed to the housing insert with mechanical fasteners. Spacing between the window and the first converter plate and between the converter plates is critical because of helium channel cooling flow requirements. Further, accurate channel spacing between the last converter plate and the first target plate is required. This spacing accuracy requires a close fit between the target holder sides and the mating target housing surfaces. 


\section{Converter \\ Plates}

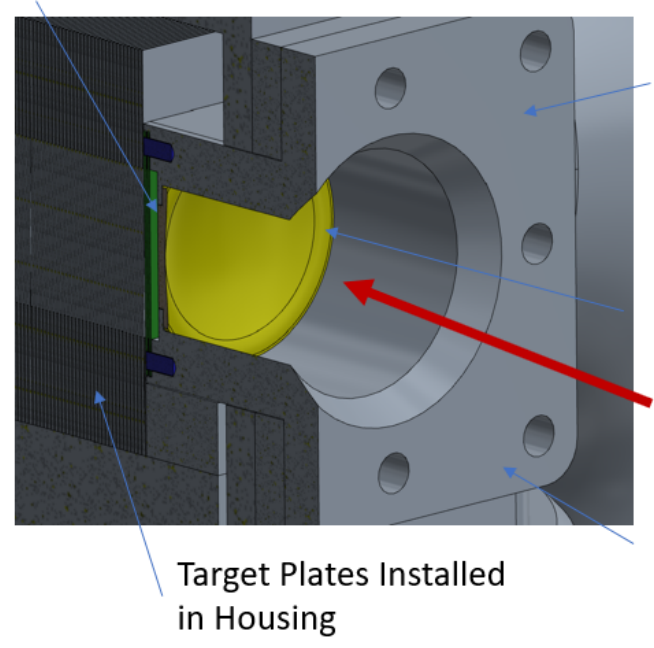

Converter Mechanical

Plates Fasteners (Typ.)

Target Housing

Helium Supply Inlet to Target

Window

Beam

Window

Mount

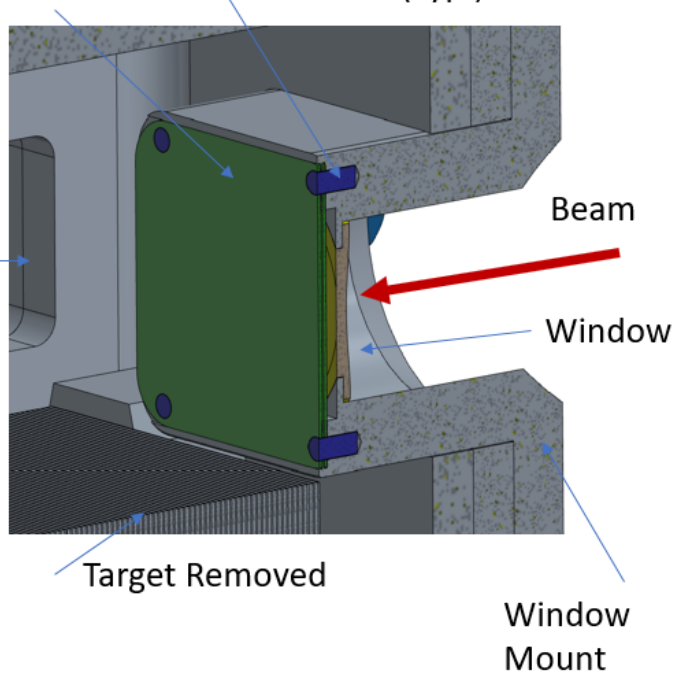

FIGURE 14 Details of the window and converter mounting.

\section{CONCLUSION}

Results of the Monte Carlo simulations for the full-scale target for accelerator-based production of ${ }^{99} \mathrm{Mo}$ demonstrated a moderate $(\sim 5.5 \%)$ increase in the production of the isotope between a pure Mo target configuration and the target with a high- $Z$ converter incorporated. This advantage holds even for the target configuration where the first two Mo disks are replaced with high- $\mathrm{Z}$ material. In this case, the constant geometrical size of the target allows incorporation of the target with converter into the current production target housing configuration.

Thermo-hydraulic calculations for the target showed adequate cooling of the window, converter and Mo disks. Regardless of which material is picked for the converter, the maximum temperature stays well below the melting point. Of the three materials evaluated for the converter, platinum looks most promising because of its chemical stability. (If helium in the cooling system is contaminated with oxygen, both tantalum and tungsten are easily oxidized at elevated temperatures and oxide particles can contaminate the cooling system and the target.) 


\section{REFERENCES}

1. https://www.iba-industrial.com/sites/default/files/290319_iba_industrial-northstar-en_1.pdf

2. A. Ferrari, P.R. Sala, A. Fasso, and J. Ranft, FLUKA: A Multi-Particle Transport Code, CERN-2005-10 (2005), INFN/TC_05/11, SLAC-R-773

3. A. Ferrari, P.R. Sala, in Proceedings of the International Conference on Monte Carlo Simulation in High-Energy and Nuclear Physics, MC93 (World Scientific, 1994), p. 277.

4. A. Fasso, A. Ferrari, J. Ranft, P.R. Sala, in Proceedings of the Specialists' Meeting on Shielding Aspects of Accelerators, Targets \& Irradiation Facilities, Arlington, TX, USA, April 28-29, 1994 (OECD Documents, Paris, 1995), pp. 287-304.

5. https://www-nds.iaea.org/exfor/

6. P. Tkac, D. Rotsch, S. Chemerisov, J. Bailey, J. Krebs, G. Vandegrift, Optimization of the Dissolution of Molybdenum Disks: FY-16 Results. Argonne National Laboratory Report ANL/NE-16/28, 2016.

7. ANSYS CFX, Release 2019 R2, 2019. Ansys, Inc., Canonsburg, PA. 


\section{APPENDIX: ANALYTICAL CALCULATIONS FOR THE SECOND CONVERTER DISK}

Disk 2 Thermal hydraulic cfx check

Helium properties at operating conditions

$$
\begin{aligned}
& \mathrm{p}_{\mathrm{atm}}:=14.7 \mathrm{psi} \quad \text { Atmospheric pressure } \\
& \mathrm{p}_{\mathrm{op}}:=290 \mathrm{psi} \quad \text { He operating pressure } \quad \mathrm{p}_{\mathrm{op}}=1.999 \times 10^{6} \mathrm{~Pa} \\
& \rho_{\text {HeAtm }}:=0.01 \frac{\mathrm{lb}}{\mathrm{ft}^{3}} \quad \text { He density at STP } \\
& \rho_{\text {op }}:=\rho_{\text {HeAtm }} \cdot \frac{p_{\text {op }}}{P_{\text {atm }}}=3.16 \frac{\mathrm{kg}}{\mathrm{m}^{3}} \quad \begin{array}{l}
\text { He density at operating pressure } \\
\text { Table chk @ 20bar }=3.18 \mathrm{~kg} / \mathrm{m}^{\wedge} 3
\end{array} \\
& \mathrm{p}_{\text {bar }}:=\frac{\mathrm{p}_{\text {op }}}{\mathrm{p}_{\mathrm{atm}}}=19.728 \quad \text { Operating pressure in bars } \\
& \mathrm{k}_{\mathrm{He}}:=0.153 \frac{\mathrm{W}}{\mathrm{m} \cdot \mathrm{K}} \\
& \mathrm{k}_{\mathrm{He}}=0.088 \cdot \frac{\mathrm{Btu}}{\mathrm{hr} \cdot \mathrm{ft} \cdot \mathrm{R}} \quad \text { Thermal conductivity of } \mathrm{He} \\
& \mathrm{Pr}_{\mathrm{He}}:=0.7 \quad \text { From table - constant wrt } \\
& \mu_{\mathrm{He}}:=186 \cdot 10^{-7} \frac{\mathrm{N} \cdot \mathrm{s}}{\mathrm{m}^{2}} \quad \text { Dynamic viscosity of } \mathrm{He} \\
& \mu_{\mathrm{He}}=1.25 \times 10^{-5} \cdot \frac{\mathrm{lbm}}{\mathrm{ft} \cdot \mathrm{s}} \quad \mu_{\mathrm{He}}=1.86 \times 10^{-5} \cdot \mathrm{Pa} \cdot \mathrm{s} \\
& \nu_{\mathrm{He}}:=\frac{\mu_{\mathrm{He}}}{\rho_{\mathrm{op}}}=6.336 \times 10^{-5} \cdot \frac{\mathrm{ft}^{2}}{\mathrm{~s}} \quad \text { Kinematic viscosity of He at operating pressure } \\
& \mathrm{C}_{\mathrm{He}}:=\frac{\mathrm{Pr}_{\mathrm{He}}{ }^{-\mathrm{k}} \mathrm{He}}{\mu_{\mathrm{He}}}=1.375 \cdot \frac{\mathrm{Btu}}{\mathrm{lb} \cdot \mathrm{R}} \quad \mathrm{C}_{\mathrm{P}_{\mathrm{He}}}=5.758 \times 10^{3} \cdot \frac{\mathrm{J}}{\mathrm{kg} \cdot \mathrm{K}} \quad \text { Heat capacity of } \mathrm{He}
\end{aligned}
$$




\section{Disk2 Convective Coefficient}

$$
\begin{aligned}
& \mathrm{w}_{\mathrm{chn} \mathrm{P}}:=0.25 \mathrm{~mm} \quad \text { Channel width between disk } 2 \text { and } 3 \\
& \mathrm{D}_{\mathrm{chn} P}:=2 \cdot \mathrm{w}_{\mathrm{chn}} \mathrm{P} \quad \text { Hydraulic diameter } \\
& \mathrm{v}_{\text {chn P }}:=112 \frac{\mathrm{m}}{\mathrm{s}} \quad \begin{array}{l}
\text { Average He flowvelocity in channel } \\
\text { between disk } 2 \text { and } 3 \text { from CFX results }
\end{array} \\
& \operatorname{Re}_{\text {chn } \mathrm{P}}:=\frac{\mathrm{v}_{\text {chn }} \mathrm{P} \cdot \mathrm{D}_{\text {chnn } \mathrm{P}}}{v_{\mathrm{He}}}=9.514 \times 10^{3} \quad \text { Reynolds number }>6,000, \text { turbulent flow } \\
& \mathrm{Nu}_{\mathrm{chnP}}:=0.023 \cdot \operatorname{Re}_{\mathrm{chnP}}{ }^{.8} \cdot \mathrm{Pr}_{\mathrm{He}}{ }^{.33}=31.139 \quad \text { Nuss elt number for turbulent flow } \\
& h_{\text {chnP }}:=\frac{\mathrm{Nu}_{\mathrm{chnP}} \cdot \mathrm{k}_{\mathrm{He}}}{\mathrm{D}_{\mathrm{chn} \mathrm{P}}}=1.678 \times 10^{3} \cdot \frac{\mathrm{Btu}}{\mathrm{hr} \cdot \mathrm{ft}^{2} \cdot \Delta^{\circ} \mathrm{F}} \\
& h_{\text {chnP }}=9.529 \times 10^{3} \cdot \frac{\mathrm{W}}{\mathrm{m}^{2} \cdot \mathrm{K}}
\end{aligned}
$$

\section{Disk 2 Heat Transfer}

$$
\begin{aligned}
& q_{3 \mathrm{p}}:=6.471 \cdot 10^{10} \frac{\mathrm{W}}{\mathrm{m}^{3}} \quad \text { Internal heat generation in œenter of disk } 2 \\
& \mathrm{t}_{\text {disk } 2}:=0.25 \mathrm{~mm}
\end{aligned}
$$

$$
\begin{array}{ccc}
\mathrm{T}_{\mathrm{he}}:=70^{\circ} \mathrm{F} & \mathrm{T}_{\mathrm{he}}=21.111 \cdot{ }^{\circ} \mathrm{C} & \begin{array}{l}
\text { Helium } \\
\text { te mperature }
\end{array} \\
\mathrm{kPt}_{\mathrm{Pt}}:=85 \frac{\mathrm{W}}{\mathrm{m} \cdot \mathrm{K}} & \text { Average thermal condudivity of Platinum }
\end{array}
$$$$
\mathrm{T}_{\max }:=\mathrm{q}_{3 \mathrm{p}} \cdot \mathrm{t}_{\text {disk } 2} \cdot\left(\frac{\mathrm{t}_{\text {disk } 2}}{2 \cdot \mathrm{k}_{\mathrm{Pt}}}+\frac{1}{\mathrm{~h}_{\mathrm{chnP}}}\right)+\mathrm{T}_{\mathrm{he}}=3.169 \times 10^{3} \cdot{ }^{\circ} \mathrm{F}
$$

$$
\mathrm{T}_{\max }=1.743 \times 10^{3} \cdot{ }^{\circ} \mathrm{C}
$$

Maximum temperature in disk2 assuming a 1-D, 1/2 symmetry heat transfer model with internal resistance and one corvective and one insulated boundary and no radiant heat

$\mathrm{T}_{\text {surf }}:=\frac{\mathrm{q}_{3 \mathrm{p}} \cdot \mathrm{t}_{\text {disk2 } 2}}{\mathrm{~h}_{\text {chnP }}}+\mathrm{T}_{\text {he }}=3.126 \times 10^{3} \cdot{ }^{\circ} \mathrm{F}$ transfer

$\mathrm{T}_{\text {surf }}=1.719 \times 10^{3} \cdot{ }^{\circ} \mathrm{C}$

inum wall surface temperature in coolant channel 



\section{Argonne}

\section{Experimental Operations and Facilities Division}

Argonne National Laboratory

9700 South Cass Avenue, Bldg. 362

Lemont, IL 60439-4832

www.anl.gov 